\title{
Receiver Operating Characteristic Curve Analysis of SEER Medulloblastoma and Primitive Neuroectodermal Tumor (PNET) Outcome Data: Identification and Optimization of Predictive Models
}

\author{
Min Rex Cheung
}

\begin{abstract}
Purpose: This study used receiver operating characteristic curves to analyze Surveillance, Epidemiology and End Results (SEER) medulloblastoma (MB) and primitive neuroectodermal tumor (PNET) outcome data. The aim of this study was to identify and optimize predictive outcome models. Materials and Methods: Patients diagnosed from 1973 to 2009 were selected for analysis of socio-economic, staging and treatment factors available in the SEER database for MB and PNET. For the risk modeling, each factor was fitted by a generalized linear model to predict the outcome (brain cancer specific death, yes/no). The area under the receiver operating characteristic curve (ROC) was computed. Similar strata were combined to construct the most parsimonious models. A Monte Carlo algorithm was used to estimate the modeling errors. Results: There were 3,702 patients included in this study. The mean follow up time (S.D.) was 73.7 (86.2) months. Some $40 \%$ of the patients were female and the mean (S.D.) age was 16.5 (16.6) years. There were more adult MB/PNET patients listed from SEER data than pediatric and young adult patients. Only $12 \%$ of patients were staged. The SEER staging has the highest ROC (S.D.) area of $0.55(0.05)$ among the factors tested. We simplified the 3-layered risk levels (local, regional, distant) to a simpler non-metastatic (I and II) versus metastatic (III) model. The ROC area (S.D.) of the 2-tiered model was $0.57(0.04)$. Conclusions: ROC analysis optimized the most predictive SEER staging model. The high under staging rate may have prevented patients from selecting definitive radiotherapy after surgery.
\end{abstract}

Keywords: SEER - Medulloblastoma - PNET - ROC - Radiotherapy

Asian Pac J Cancer Prev, 15 (16), 6781-6785

\section{Introduction}

Modeling risk grouping for medulloblastoma (MB) and Primitive Neuroectodermal Tumor (PNET) is an ongoing process (Packer et al., 2012; Smee et al., 2012; von Hoff and Rutkowski, 2012). MB and PNET are the most common brain tumors in children (Packer et al., 2012; Smee et al., 2012; von Hoff and Rutkowski, 2012). The cause specific survival rates for both childhood and adult with MB or PNET are about $70 \%$ (Packer et al., 2012; Smee et al., 2012; Smoll, 2012; von Hoff and Rutkowski, 2012) and this study. Thus there is room for improvement in the treatment outcome. This study uses receiver operating characteristic curve to analyze Surveillance, Epidemiology and End Results (SEER) MB/ PNET outcome data. The MB and PNET have been noted to have similar clinical course and age distribution (Smoll, 2012). The aim of this study was to identify and optimize predictive MB/PNET models to aid treatment and patient selection. This study also examined why some predictive models may not work as expected.

Surveillance Epidemiology and End Results (SEER) is a public use cancer registry of United States of America (US). SEER is funded by National Cancer Institute and Center for Disease Control to cover $28 \%$ of all oncology cases in US. SEER started collecting data in 1973 for 7 states and cosmopolitan registries. Its main purpose is through collecting and distributing data on cancer, it strives to decrease the burden of cancer. SEER data are used widely as a bench-mark data source for studying MB/PNET cancer outcomes in US and in other countries (Barnholtz-Sloan et al., 2005; Bishop et al., 2012; Curran et al., 2009; Deorah et al., 2006; Gatta et al., 2002; Halperin et al., 2004; Lai, 2008; Smoll, 2012). The extensive ground coverage by the SEER data is ideal for identifying the disparity in oncology outcome and treatment in different geographical and cultural areas (Cheung, 2013a, 2013b, 2013c; Cheung, 2012; Cheung, 2013; Downing et al., 2010; Gross et al., 2008; Harlan et al., 1995; Lund et al., 2008; Martinez et al., 2010; Martinez 
Table 1. Risk Models Including Socio-Demographic, Tumor and Treatment Risk Factors for Disparity in Outcomes of Medulloblastoma and PNET

\begin{tabular}{|c|c|c|c|c|c|c|c|c|c|c|c|}
\hline \multicolumn{2}{|c|}{ Initial univariate risk models } & \multirow{2}{*}{$\begin{array}{l}\text { Number } \\
3702\end{array}$} & \multirow[t]{2}{*}{$\%$} & \multirow[t]{2}{*}{ Model } & \multirow[t]{2}{*}{$\begin{array}{l}\text { ROC } \\
\text { Area }\end{array}$} & \multirow[t]{2}{*}{ S.D. } & \multicolumn{5}{|c|}{$\begin{array}{l}\text { ROC } \\
\text { Area }\end{array}$} \\
\hline Study population & & & & & & & & & & & \\
\hline \multirow[t]{4}{*}{ Age of diagnosis } & Mean & 16.57 & & & & & & & & & \\
\hline & S.D. & 16.61 & & & & & & & & & \\
\hline & $\geq 20$ years old & 2506 & & & 0.524 & 0.01 & 0.52 & 0.52 & 0.53 & 0.53 & 0.52 \\
\hline & $<20$ years & 1196 & & & & & & & & & \\
\hline \multirow{2}{*}{$\begin{array}{l}\text { Follow up } \\
\text { (months) }\end{array}$} & Mean & 73.74 & & & & & & & & & \\
\hline & S.D. & 86.2 & & & & & & & & & \\
\hline \multirow[t]{2}{*}{ Sex } & Female & 1499 & 40.48 & & 0.524 & 0.01 & 0.53 & 0.52 & 0.53 & 0.51 & 0.53 \\
\hline & Male & 2203 & 59.49 & & & & & & & & \\
\hline \multirow{8}{*}{$\begin{array}{l}\text { First malignant } \\
\text { primary } \\
\text { indicator } \\
\text { SEER historic } \\
\text { stage A }\end{array}$} & Yes & 3608 & 97.43 & & 0.502 & 0 & 0.5 & 0.5 & 0.5 & 0.51 & 0.5 \\
\hline & No & 94 & 2.54 & & & & & & & & \\
\hline & Localized (I) & 137 & 3.70 & I, II, III & 0.552 & 0.04 & 0.53 & 0.61 & 0.51 & 0.52 & 0.59 \\
\hline & Regional (II) & 150 & 4.05 & optimized & & & & & & & \\
\hline & Distant (III) & 128 & 3.46 & $(\mathrm{I}, \mathrm{II})$ vs III & 0.568 & 0.04 & 0.56 & 0.51 & 0.57 & 0.62 & 0.58 \\
\hline & Unstaged & 3272 & 88.36 & & & & & & & & \\
\hline & Blank(s) & 14 & 0.38 & & & & & & & & \\
\hline & Localized/regional (Prostate cases) & 1 & 0.03 & & & & & & & & \\
\hline \multirow{12}{*}{$\begin{array}{l}\text { Rural-Urban } \\
\text { Continuum } \\
\text { Code } 2003\end{array}$} & Counties in metropolitan areas ge & 2312 & 62.44 & & 0.504 & 0.01 & 0.51 & 0.5 & 0.5 & 0.51 & 0.5 \\
\hline & 1 million pop & & & & & & & & & & \\
\hline & $\begin{array}{l}\text { Counties in metropolitan areas } \\
\text { of } 250,000 \text { to } 1 \text { million pop }\end{array}$ & 765 & 20.66 & & & & & & & & \\
\hline & $\begin{array}{l}\text { Urban pop of ge } 20,000 \\
\text { adjacent to a metropolitan area }\end{array}$ & 81 & 2.19 & & & & & & & & \\
\hline & $\begin{array}{l}\text { Urban pop of ge } 20,000 \\
\text { not adjacent to a metropolitan area }\end{array}$ & 48 & 1.30 & & & & & & & & \\
\hline & $\begin{array}{l}\text { Counties in metropolitan areas } \\
\text { of lt } 250 \text { thousand pop }\end{array}$ & 288 & 7.78 & & & & & & & & \\
\hline & $\begin{array}{l}\text { Comp rural lt } 2,500 \text { urban pop, } \\
\text { adjacent to a metro area }\end{array}$ & 12 & 0.32 & & & & & & & & \\
\hline & $\begin{array}{l}\text { Urban pop of } 2,500 \text { to } 19,999 \text {, } \\
\text { adjacent to a metro area }\end{array}$ & 110 & 2.97 & & & & & & & & \\
\hline & $\begin{array}{l}\text { Urban pop of } 2,500 \text { to } 19,999, \\
\text { not adjacent to a metro area }\end{array}$ & 64 & 1.73 & & & & & & & & \\
\hline & $\begin{array}{l}\text { Comp rural lt } 2,500 \text { urban pop, } \\
\text { not adjacent to metro area }\end{array}$ & 17 & 0.46 & & & & & & & & \\
\hline & Unknown/missing/no match & 1 & 0.03 & & & & & & & & \\
\hline & $\begin{array}{l}\text { Unknown/missing/no match } \\
\text { (Alaska - Entire State) }\end{array}$ & 4 & 0.11 & & & & & & & & \\
\hline \multirow{4}{*}{$\begin{array}{l}\text { County Family } \\
\text { Income } \\
\text { County \% } \\
\text { college graduate }\end{array}$} & $>=50000$ & 2163 & 58.43 & & 0.504 & 0.01 & 0.5 & 0.5 & 0.51 & 0.51 & 0.5 \\
\hline & $<50000$ & 1539 & 41.57 & & & & & & & & \\
\hline & $>=25 \%$ & 1894 & 51.16 & & 0.508 & 0.01 & 0.51 & 0.51 & 0.5 & 0.52 & 0.5 \\
\hline & $<25 \%$ & 1808 & 48.84 & & & & & & & & \\
\hline \multirow[t]{2}{*}{ Race } & Others & 3375 & 91.17 & & 0.506 & 0.01 & 0.5 & 0.51 & 0.51 & 0.51 & 0.5 \\
\hline & Black & 327 & 8.83 & & & & & & & & \\
\hline \multirow{7}{*}{$\begin{array}{l}\text { Radiation } \\
\text { treatment given }\end{array}$} & Radiation after surgery & 2256 & 60.92 & & & & & & & & \\
\hline & $\begin{array}{l}\text { No radiation and/or } \\
\text { cancer-directed surgery }\end{array}$ & 1325 & 35.78 & & & & & & & & \\
\hline & $\begin{array}{l}\text { Intraoperative rad with } \\
\text { other rad before/after surgery }\end{array}$ & 3 & 0.08 & & & & & & & & \\
\hline & Intraoperative radiation & 2 & 0.05 & & & & & & & & \\
\hline & Radiation prior to surgery & 94 & 2.54 & & & & & & & & \\
\hline & Sequence unknown, but both were gi & iven 15 & 0.41 & & & & & & & & \\
\hline & Radiation before and after surgery & 7 & 0.19 & & & & & & & & \\
\hline \multirow{8}{*}{$\begin{array}{l}\text { Reason } \\
\text { no cancer-directed } \\
\text { surgery }\end{array}$} & Surgery performed & 3289 & 88.82 & & & & & & & & \\
\hline & $\begin{array}{l}\text { Recommended } \\
\text { but not performed, patient refused }\end{array}$ & 4 & 0.11 & & 0.506 & 0.01 & 0.51 & 0.51 & 0.51 & 0.5 & 0.5 \\
\hline & $\begin{array}{l}\text { Recommended but not performed, } \\
\text { unknown reason }\end{array}$ & 113 & 3.05 & & & & & & & & \\
\hline & $\begin{array}{l}\text { Unknown; death certificate } \\
\text { or autopsy only case }\end{array}$ & 22 & 0.59 & & & & & & & & \\
\hline & Not recommended & 243 & 6.56 & & & & & & & & \\
\hline & $\begin{array}{l}\text { Not recommended, } \\
\text { contraindicated due to other condition }\end{array}$ & 23 & 0.62 & & & & & & & & \\
\hline & Recommended, unknown if performe & 7 & 0.19 & & & & & & & & \\
\hline & $\begin{array}{l}\text { Not performed, patient died } \\
\text { prior to recommended surgery }\end{array}$ & 1 & 0.03 & & & & & & & & \\
\hline $\mathrm{COD}$ to site rec $\mathrm{KM}$ & Alive & 2031 & 54.85 & & & & & & & & \\
\hline & Brain and Other Nervous System & 1023 & 27.63 & & & & & & & & \\
\hline & Others & 648 & 17.53 & & & & & & & & \\
\hline
\end{tabular}


ROC Curve Analysis of SEER Medulloblastoma and PNET Outcome Data: Optimization of Predictive Models

et al., 2012; Schlichting et al., 2012; Shavers et al., 2003; Wampler et al., 2005; Yao et al., 2012). In addition to the biological staging factors and the treatment factors, this database also contains a large number of county level socio-economic factors data. This study aimed to identify barriers to good treatment outcome that may be discernable from a national database.

SEER registry has massive amount of data available for analysis, however, manipulating this data pipeline could be challenging. SEER Clinical Outcome Prediction Expert (SCOPE) (Cheung, 2012) is designed and implemented to mine SEER data and construct accurate and efficient prediction models (Cheung et al., 2001a, 2001b).

\section{Materials and Methods}

The data were obtained from SEER 18 database. SEER is a public use database that can be used for analysis with no internal review board approval needed. SEER*Stat was used for listing the cases. The filter used was: 'Site and Morphology.AYA site recode' = '3.4. Medulloblastoma and other PNET'. This study explored a long list of socio-economic, staging and treatment factors that were available in the SEER database. We have designed and implemented SEER Clinical Outcome Prediction Expert (SCOPE) for this purpose. The codes of SCOPE have been posted on Matlab Central. SCOPE has a number of utility programs that are adapted to handle the large SEER data pipeline. All statistics and programming were performed in Matlab. Each risk factor was fitted by a Generalized Linear Model to predict the outcome (brain and other nervous system specific death). The areas under the receiver operating characteristic curve (ROC) were computed. Similar strata were fused to make more efficient models if the ROC performance did not degrade (Cheung et al., 2001a, 2001b). In addition, it also implemented binary fusion and optimization to streamline the risk stratification by combining risk strata when possible. SCOPE uses Monte Carlo sampling and replacement to estimate the modeling errors and allows t-testing of the areas under the ROC. SCOPE provides SEER-adapted programs for user friendly exploratory studies, univariate recoding and parsing.

\section{Results}

There were 3702 patients included in this study (Table 1). The followup (S.D.) was 73.7 (86.2) months. $40 \%$ of the patients were female. The mean (S.D.) age was 16.5 (16.6) years. There were more adult MB patients listed from SEER data than the pediatric and young adult patients. Only $12 \%$ of patients were staged. The SEER staging has the highest ROC (S.D.) area of $0.55(0.05)$ among the factors tested in Table 1.

SEER Clinical Outcome Prediction Expert was used to perform ROC curve and area under the curve calculations. In this example, the ROC area of the 3-tiered SEER staging model as computed for 5 random samples (Table $1)$. The results are shown in the upper panels. In the lower panels, SCOPE simplified the 3-layered risk levels (local, regional, distant) to a simpler non-metastatic (I and II)
Table 2. Risk of Cause Specific Mortality (\%) for Different Models

\begin{tabular}{llcr}
\hline Models & & $\begin{array}{c}\text { Outcome } \\
\% \text { mortality }\end{array}$ & No. at risk \\
\hline Age of diagnosis & $<20$ years old & 0.29 & 2506 \\
& $\geq 20$ years old & 0.25 & 1196 \\
Surgical treatment & Yes & 0.28 & 3289 \\
& No & 0.28 & 413 \\
Radiotherapy & Yes & 0.27 & 2256 \\
SEER staging & No & 0.28 & 1446 \\
& Local & 0.04 & 137 \\
Optimized SEER staging & Regional & 0.03 & 150 \\
& Metastatic & 0.06 & 128 \\
& Local and regional & 0.04 & 287 \\
& Metastatic & 0.06 & 128 \\
\hline
\end{tabular}

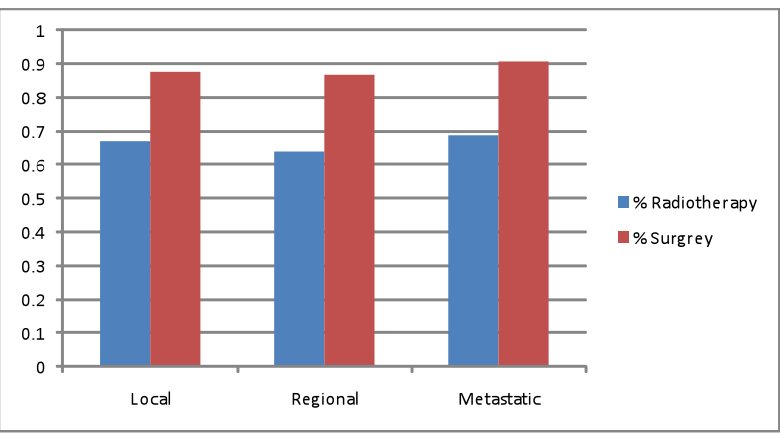

Figure 1. The Completely Staged Patients were Found to Do Better Than the Overall Cohort. Although most patients were treated with surgery, radiotherapy was about 15$20 \%$ under-utilized when compared with surgery

versus metastatic (III) model. The ROC area (S.D.) of the 2-tiered model was $0.57(0.04)$ based on 5 random samples with replacement from the SEER data. Rural residence, county's family income level, county' education attainment and race were tested as socio-economic barriers to good outcome. None of these factors were predictive of brain cancer specific survival. They had a ROC area of around 0.5 that is expected for a random variable with no predictive power.

The staged patients fared better than the overall cohort (Table 2). Age older than 20 years old did not correlate with higher percentage mortality during this study period from 1977 to 2009 . Neither surgery nor radiotherapy was associated with a lower risk of cause specific mortality in the overall cohort. The completely staged patients were found to do better than the overall cohort. Although most patients were treated with surgery, radiotherapy was about 15-20\% under-utilized when compared with surgery (Figure 1). Given the aggressive nature of this disease, these patients would uniformly require combined modality treatment.

\section{Discussion}

This study is interested in constructing models that will aid patient and treatment selection for MB/PNET cancer patients. To that end, this study examined the ROC models (Hanley and McNeil, 1982) of a long list of potential explanatory factors (Table 1). ROC models take into account both sensitivity and specificity of the prediction. Ideal model would have a ROC area of 1 and a random 
model is expected to have an area of 0.5 (Hanley and McNeil, 1982). For example, a clinical ROC model can be used to predict if a patient receiving the recommended treatment will die from the disease. The SEER staging is most predictive of patient outcome (Table 1). After binary fusion, it reduces to non-metastatic versus metastatic classification of the MB/PNET patients (Table 1). Such efficient model may aid in reducing patients needed for clinical trials because it has fewer risk groups to balance.

When there are competing prediction or prognostic models, the most efficient (i.e. the simplest) model is thought to prevail (D'Amico et al., 1998). This has an information theoretic (D'Amico et al., 1998) underpinning. For practical purposes, simpler models require fewer patients for a randomized trials because fewer risk strata need to be balanced. In the clinic, simpler models are easier to use. SCOPE streamlined ROC models by binary fusion (Table 1). Two adjacent strata were tested iteratively to see if they could be combined without sacrificing the higher predictive power usually belong to the more complex models. This study has shown that SCOPE can built efficient and accurate prediction models.

For surgery and radiotherapy, the ROC areas were modest (0.5). Low ROC areas imply the information content (i.e. the staging accuracy) of the models may be limited. It is consistent with the fact that only $12 \%$ patients had complete SEER staging (Table 2). In addition, the outcome of the completely staged patients was much more superior when compared with the entire cohort (Table 2). It may be a consequence of having a better guidance model in treatment and patient selection.

In conclusion, this study has identified the staging models are the most prognostic of treatment outcomes of medulloblastoma and PNET patients. The high under-staging rates may have prevented patients from selecting definitive local therapy (Fig. 1). The poor rates of radiotherapy after surgery use may have contributed to the poor outcome in these patients with this aggressive disease.

\section{References}

Barnholtz-Sloan JS, Severson RK, Stanton B, Hamre M, Sloan AE (2005). Pediatric brain tumors in non-Hispanics, Hispanics, African Americans and Asians: differences in survival after diagnosis. Cancer Causes Control, 16, 587-92.

Bishop AJ, McDonald MW, Chang AL, Esiashvili N (2012). Infant brain tumors: incidence, survival, and the role of radiation based on Surveillance, Epidemiology and End Results (SEER) Data. Int J Radiat Oncol Biol Phys, 82, 341-7.

Cheung MR (2013a). African American race and low income neighborhoods decrease cause specific survival of endometrial cancer: a SEER analysis. Asian Pac J Cancer Prev, 14, 2567-70.

Cheung MR (2013b). Low income and rural county of residence increase mortality from bone and joint sarcomas. Asian Pac $J$ Cancer Prev, 14, 5043-7.

Cheung MR (2013c). Using SEER data to quantify effects of low income neighborhoods on cause specific survival of skin melanoma. Asian Pac J Cancer Prev, 14, 3219-21.

Cheung R (2012). Poor treatment outcome of neuroblastoma and other peripheral nerve cell tumors may be related to under usage of radiotherapy and socio-economic disparity: a US SEER data analysis. Asian Pac J Cancer Prev, 13, 4587-91.

Cheung R. (2013). Racial and social economic factors impact on the cause specific survival of pancreatic cancer: a SEER survey. Asian Pac J Cancer Prev, 14, 159-63.

Cheung R, Altschuler MD, D'Amico AV, et al (2001a). ROCoptimization may improve risk stratification of prostate cancer patients. Urology, 57, 286-90.

Cheung R, Altschuler MD, D'Amico AV, et al (2001b). Using the receiver operator characteristic curve to select pretreatment and pathologic predictors for early and late post-prostatectomy PSA failure. Urology, 58, 400-5.

Curran EK, Le GM, Sainani KL, Propp JM, Fisher PG (2009). Do children and adults differ in survival from medulloblastoma? A study from the SEER registry. $J$ Neurooncol, 95, 81-5.

D'Amico AV, Desjardin A, Chung A, et al (1998). Assessment of outcome prediction models for patients with localized prostate carcinoma managed with radical prostatectomy or external beam radiation therapy. Cancer, 82, 1887-96.

Deorah S, Lynch CF, Sibenaller ZA, Ryken TC (2006). Trends in brain cancer incidence and survival in the United States: Surveillance, Epidemiology, and End Results Program, 1973 to 2001. Neurosurg Focus, $20,1$.

Downing S, Ahuja N, Oyetunji TA, Chang D, Frederick WA (2010). Disparity in limb-salvage surgery among sarcoma patients. Am J Surg, 199, 549-53.

Gatta G, Capocaccia R, Coleman MP, Ries LA, Berrino F (2002). Childhood cancer survival in Europe and the United States. Cancer, 95, 1767-72.

Gross CP, Smith BD, Wolf E, Andersen M (2008). Racial disparities in cancer therapy: did the gap narrow between 1992 and 2002? Cancer, 112, 900-8.

Halperin EC, Miranda ML, Watson DM, George SL, Stanberry M (2004). Medulloblastoma and birth date: evaluation of 3 U.S. datasets. Arch Environ Health, 59, 26-30.

Hanley JA and McNeil BJ. (1982). The meaning and use of the area under a receiver operating characteristic (ROC) curve. Radiology, 143, 29-36.

Harlan L, Brawley O, Pommerenke F, Wali P, Kramer B (1995). Geographic, age, and racial variation in the treatment of local/regional carcinoma of the prostate. JCO, 13, 93-100.

Lai R (2008). Survival of patients with adult medulloblastoma: a population-based study. Cancer, 112, 1568-74.

Lund MJ, Brawley OP, Ward KC, et al (2008). Parity and disparity in first course treatment of invasive breast cancer. Breast Cancer Res Treat, 109, 545-57.

Martinez SR, Beal SH, Chen SL, et al (2010). Disparities in the use of radiation therapy in patients with local-regionally advanced breast cancer. Int J Radiat Oncol Biol Phys, 78, 787-92.

Martinez SR, Tseng WH, Canter RJ, et al (2012). Do radiation use disparities influence survival in patients with advanced breast cancer? Cancer, 118, 196-204.

Packer RJ, Macdonald T, Vezina G, Keating R, Santi M (2012). Medulloblastoma and primitive neuroectodermal tumors. Handb Clin Neurol, 105, 529-48.

Schlichting JA, Soliman AS, Schairer C, et al (2012). Association of inflammatory and noninflammatory breast cancer with socioeconomic characteristics in the Surveillance, Epidemiology, and End Results database, 2000-2007. Cancer Epidemiol Biomarkers Prev, 21, 155-65.

Shavers VL, Harlan LC, Stevens JL (2003). Racial/ethnic variation in clinical presentation, treatment, and survival among breast cancer patients under age 35. Cancer, 97, 134-47.

Smee RI, Williams JR, De-Loyde KJ, Meagher NS, Cohn R (2012). Medulloblastoma: progress over time. J Med 
ROC Curve Analysis of SEER Medulloblastoma and PNET Outcome Data: Optimization of Predictive Models Imaging Radiat Oncol, 56, 227-34.

Smoll NR (2012). Relative survival of childhood and adult medulloblastomas and primitive neuroectodermal tumors (PNETs). Cancer, 118, 1313-22.

von Hoff K and Rutkowski S (2012). Medulloblastoma. Curr Treat Options Neurol, 14, 416-26.

Wampler NS, Lash TL, Silliman RA, Heeren TC (2005). Breast cancer survival of American Indian/Alaska Native women, 1973-1996. Soz Praventivmed, 50, 230-7.

Yao N, Lengerich EJ, Hillemeier MM (2012). Breast cancer mortality in Appalachia: reversing patterns of disparity over time. J Health Care Poor Underserved, 23, 715-25. 